\title{
The effect of heartburn and acid reflux on the severity of nausea and vomiting of pregnancy
}

\author{
Simerpal Kaur Gill MSc ${ }^{1,2}$, Caroline Maltepe BA ${ }^{1}$, Gideon Koren MD ${ }^{1,2}$
}

SK Gill, C Maltepe, G Koren. The effect of heartburn and acid reflux on the severity of nausea and vomiting of pregnancy. Can J Gastroenterol 2009;23(4):270-272.

BACKGROUND: Heartburn (HB) and acid reflux (RF) in the nonpregnant population can cause nausea and vomiting; therefore, it is plausible that in women with nausea and vomiting of pregnancy (NVP), HB/RF may increase the severity of symptoms.

OBJECTIVE: To determine whether HB/RF during pregnancy contribute to increased severity of NVP.

METHODS: A prospectively collected cohort of women who were experiencing NVP and HB, RF or both $(n=194)$ was studied. The Pregnancy-Unique Quantification of Emesis and Nausea (PUQE) scale and its Well-being scale was used to compare the severity of the study cohort's symptoms. This cohort was compared with a group of women experiencing NVP but no HB/RF $(n=188)$. Multiple linear regression was used to control for the effects of confounding factors. RESULTS: Women with HB/RF reported higher PUQE scores $(9.6 \pm 2.6)$ compared with controls $(8.9 \pm 2.6)(P=0.02)$. Similarly, Well-being scores for women experiencing $\mathrm{HB} / \mathrm{RF}$ were lower $(4.3 \pm 2.1)$ compared with controls $(4.9 \pm 2.0)(\mathrm{P}=0.01)$. Multiple linear regression analysis demonstrated that increased PUQE scores $(\mathrm{P}=0.003)$ and decreased Well-being scores $(\mathrm{P}=0.005)$ were due to the presence of $\mathrm{HB} / \mathrm{RF}$ as opposed to confounding factors such as pre-existing gastrointestinal conditions/symptoms, hyperemesis gravidarum in previous pregnancies and comorbidities.

CONCLUSION: The present cohort study is the first to demonstrate that $\mathrm{HB} / \mathrm{RF}$ are associated with increased severity of NVP. Managing HB/RF may improve the severity of NVP.

Key Words: Acid reflux; Heartburn; Nausea and vomiting of pregnancy (NVP); PUQE

Symptoms of nausea and vomiting of pregnancy (NVP), $\checkmark$ experienced by $80 \%$ of pregnant women (1), typically start between the fourth and ninth weeks of pregnancy until the 12 th to 16 th weeks of pregnancy (2). Unfortunately, in 20\% of pregnant women, symptoms persist throughout pregnancy of which $1 \%$ to $3 \%$ of women experience hyperemesis gravidarum (2). NVP can severely affect a woman's quality of life and her ability to function, especially when the condition is improperly managed (3). Certain factors have been shown to aggravate NVP including migraine headaches (4), thyroid disorders $(4,5)$, maternal age at conception (6), gravidity (6) and the use of iron-containing prenatal multivitamin supplements (7).

Heartburn (HB) and acid reflux (RF) are common medical disorders; it has been estimated that the prevalence of gastroesophageal reflux disorders in pregnancy ranges from $40 \%$ to $85 \%(8-13)$. The onset of HB/RF can occur at any time during pregnancy. In one study (14), 52\% of symptoms began in the first trimester and almost all appeared by the second trimester, with only $8 \%$ of symptoms beginning in the third trimester.

\section{L'effet des brûlures d'estomac et du reflux acide sur la gravité des nausées et des vomissements de la grossesse}

HISTORIQUE : Chez les personnes qui ne sont pas enceintes, les brûlures d'estomac (BE) et le reflux acide (RA) peuvent provoquer des nausées et des vomissements. Il est donc plausible que, chez les femmes qui souffrent de nausées et de vomissements de la grossesse (NVG), les BE et le RA peuvent accroître la gravité des symptômes.

OBJECTIF : Déterminer si, pendant la grossesse, les BE et le RA peuvent contribuer à aggraver les NVG.

MÉTHODOLOGIE : Les auteurs ont colligé de manière prospective une cohorte de femmes qui souffraient de NVG et de BE ou de RA ou à la fois de BE et de RA ( $\mathrm{n}=194)$. Ils ont utilisé l'échelle PUQE sur la quantification des vomissements et des nausées propres à la grossesse et l'échelle de bienêtre s'y rapportant pour comparer la gravité des symptômes de la cohorte à l'étude. Ils ont comparé cette cohorte à un groupe de femmes souffrant de NVG, mais pas de BE et de RA ( $n=188)$. La régression linéaire multiple a permis de contrôler les effets des facteurs confusionnels.

RÉSULTATS : Les femmes souffrant de BE et de RA ont déclaré des indices de PUQE $(9,6 \pm 2,6)$ plus élevés que sujets témoins $(8,9 \pm 2,6)$ $(\mathrm{P}=0,02)$. De même, l'échelle de bien-être des femmes souffrant de $\mathrm{BE}$ et de RA était plus faible $(4,3 \pm 2,1)$ que celle des sujets témoins $(4,9 \pm 2,0)$ $(\mathrm{P}=0,01)$. L'analyse de régression linéaire multiple a démontré que des indices de PUQE plus élevés $(\mathrm{P}=0,003)$ et des indices de bien-être plus faibles $(\mathrm{P}=0,005)$ étaient attribuables à la présence de $\mathrm{BE}$ et de $\mathrm{RA}$ plutôt qu'à des facteurs confusionnels comme des symptômes ou des troubles gastro-intestinaux préexistants, l'hyperemesis gravidarum lors de grossesses antérieures et les comorbidités.

CONCLUSION : La présente étude de cohorte est la première à démontrer que les $\mathrm{BE}$ et le RA s'associent pour aggraver les NVG. La prise en charge des $\mathrm{BE}$ et du RA peut atténuer la gravité des NVG.

Other studies $(15,16)$ reported increased severity and frequency of symptoms as gestational age increases. Regardless of the time of onset, anecdotal clinical evidence suggests that the presence of pre-existing gastrointestinal (GI) conditions and/or symptoms, as well as $\mathrm{HB} / \mathrm{RF}$ during pregnancy aggravate nausea and vomiting $(10,11)$.

Although the symptoms of HB/RF do not differ in the pregnant versus the nonpregnant population, their etiology may $(10,11)$. Changes in motility of the GI tract due to increased levels of circulating female hormones result in increased GI tract symptoms in pregnancy $(10,11,17-19)$. Specifically, a decrease in lower esophageal sphincter pressure during pregnancy accompanied by $\mathrm{HB}$ has been demonstrated (17). Furthermore, a decrease in lower esophageal sphincter pressure occurs in the presence of estrogen and progesterone among female volunteers using oral contraceptives $(18,19)$. Similar changes in gastric motility and dysrhythmias have been observed in NVP (8). Therefore, it is biologically plausible that $\mathrm{HB} / \mathrm{RF}$ can contribute to the severity of NVP. If confirmed,

\footnotetext{
${ }^{1}$ The Motherisk Program, The Hospital for Sick Children; ${ }^{2}$ Department of Pharmacology, University of Toronto, Toronto, Ontario

Correspondence: Dr Gideon Koren, The Motherisk Program, The Hospital for Sick Children, 555 University Avenue, Toronto,

Ontario M5G 1X8. Telephone 416-813-5781, fax 416-813-7562, e-mail gkoren@sickkids.ca

Received for publication July 14, 2008. Accepted July 17, 2008
} 
TABLE 1

\begin{tabular}{|c|c|c|c|c|c|}
\hline $\begin{array}{l}\text { How many hours in the } \\
\text { past } 24 \text { hours had you } \\
\text { felt nauseated/sick to } \\
\text { stomach? }\end{array}$ & (1) & (2) & (3) & (4) & (5) \\
\hline $\begin{array}{l}\text { How many times in the } \\
\text { past } 24 \text { hours did you } \\
\text { vomit? }\end{array}$ & $\begin{array}{l}\geq 7 \\
\text { (5) }\end{array}$ & $\begin{array}{l}5-6 \\
(4)\end{array}$ & $\begin{array}{c}3-4 \\
\text { (3) }\end{array}$ & $\begin{array}{c}1-2 \\
(2)\end{array}$ & $\begin{array}{c}\text { None } \\
\text { (1) }\end{array}$ \\
\hline $\begin{array}{l}\text { How many times in the } \\
\text { past } 24 \text { hours did you } \\
\text { experience gagging, } \\
\text { retching or dry } \\
\text { heaves? }\end{array}$ & $\begin{array}{l}\text { None } \\
\text { (1) }\end{array}$ & $\begin{array}{c}1-2 \\
(2)\end{array}$ & $\begin{array}{c}3-4 \\
\text { (3) }\end{array}$ & $\begin{array}{c}5-6 \\
\text { (4) }\end{array}$ & $\begin{array}{l}\geq 7 \\
\text { (5) }\end{array}$ \\
\hline
\end{tabular}

PUQE score:

*The PUQE scale is a validated scoring system used to quantify the severity of nausea and vomiting of pregnancy based on quantification of three physical symptoms of nausea and vomiting of pregnancy (nausea, vomiting and retching) for the past 12 hours (21). We have used the modified PUQE scale that quantifies nausea, vomiting and retching for the past 24 hours

this hypothesis can lead to improvement in the management of NVP by treating symptoms of RF.

The objective of the present study was to determine whether pregnant women suffering from $\mathrm{HB}, \mathrm{RF}$ or both experience increased severity of NVP.

\section{METHODS}

The Motherisk Program, located at the Hospital for Sick Children in Toronto, Ontario, has a specialized helpline for the management of NVP. Women from Canada and the United States experiencing NVP can call a toll-free service to receive pharmacological and nonpharmacological advice regarding the management of NVP. This evidence-based counselling is based on research and continuous systematic review of all emerging clinical and experimental evidence.

For the purpose of the present study, a prospective cohort of women counselled by the NVP helpline from January 1, 2007 to December 31, 2007, was analyzed. The study group consisted of women who experienced HB/RF while suffering from NVP. A comparison cohort consisting of women who experienced NVP, but not $\mathrm{HB} / \mathrm{RF}$ was also collected from the same time period. A standard interview was conducted in which detailed quantification of symptoms was obtained using the following tools:

- the Pregnancy-Unique Quantification of Emesis and Nausea (PUQE) score (20) (Table 1);

- the Well-being score (21) ranging from 0 (the worst possible) to 10 (the best possible) was recorded based on how the woman felt overall compared with how she felt before pregnancy; and

- a self-report of how the woman perceived her NVP symptoms (mild, moderate or severe).

In addition, the time of onset of the NVP symptoms, gravidity, maternal age at conception, gestational age at the initial interview, other medical conditions, pre-existing GI conditions or symptoms, medication use and the severity of NVP in previous pregnancies were recorded.

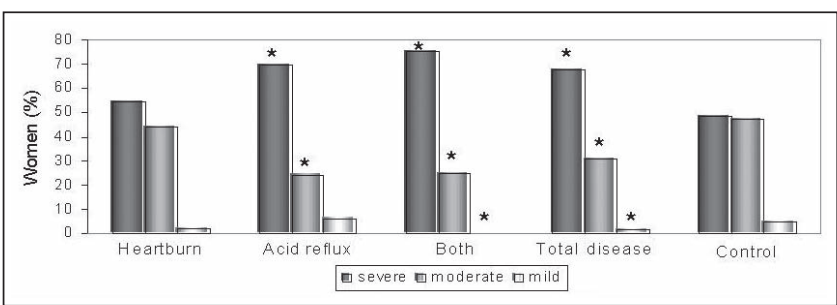

Figure 1) Self-report of severity of nausea and vomiting of pregnancy (NVP) as mild, moderate or severe by women experiencing heartburn (HB), acid reflux $(R F)$, both $H B$ and $R F$, total disease (including $\mathrm{HB}, \mathrm{RF}$ and both), or no $\mathrm{HB} / \mathrm{RF}$. $* \mathrm{P}<0.05$ compared with control

The unpaired $t$ test was used to compare the mean scores of different characteristics between the two groups. Characteristics that were found to be statistically different between the two groups were included in a multiple linear regression model to determine factors that contributed to the differences in the PUQE and Well-being scores observed between the two groups.

Statistical significance was set at $\mathrm{P}<0.05$ and conducted with the SigmaStat program version 3.1 (Systat Software Inc, USA).

\section{RESULTS}

Of 194 women in the HB/RF group, 60 experienced only HB, 42 experienced only RF, and 92 reported both HB and RF. Selfreported severity of NVP was statistically different between the groups, with $75 \%$ of women experiencing both HB and RF classifying their NVP as severe, whereas only $48 \%$ of women in the control group ( 90 of 188) classified their NVP as severe $(\mathrm{P}<0.0001)$ (Figure 1). Seventy per cent of women with RF only self-reported their NVP as severe, which was significantly higher than among controls $(\mathrm{P}=0.009)$ (Figure 1). Additionally, in the HB/RF group, there were significantly fewer women who classified their NVP as moderate $(30 \%)$ compared with controls $(40 \%)(\mathrm{P}=0.04)$, and no women experiencing both $\mathrm{HB}$ and RF classified their NVP as mild compared with $5 \%$ of controls $(\mathrm{P}=0.002)$ (Figure 1$)$.

The PUQE scores corroborated the self-reports: the mean PUQE score of women experiencing both $\mathrm{HB}$ and RF was higher (9.6 \pm 2.6$)$ compared with controls $(8.9 \pm 2.6)$; this difference in score was statistically significant $(\mathrm{P}=0.02)$ (Figure 2$)$. Women experiencing both $\mathrm{HB}$ and RF had the highest mean PUQE score $(10.0 \pm 2.4)$ which was found to be significantly higher than in controls $(\mathrm{P}=0.0004)$ (Figure 2).

The Well-being scores reflected a similar pattern. The mean score of controls $(4.9 \pm 2.0)$ was higher than in the HB/RF group $(4.3 \pm 2.1 ; \mathrm{P}=0.01)$, and significantly higher than the mean Well-being score of women experiencing both $\mathrm{HB}$ and RF (3.9 $\pm 2.1 ; \mathrm{P}=0.0004)$ (Figure 3).

Potential confounding factors were compared; no differences between control and HB/RF groups were found for maternal age at conception, gravidity, gestational age at onset of symptoms, gestational age at interview, multiple gestation and vitamin use. In contrast, there were higher rates of antiemetic use $(P=0.0001)$ and the use of antacids $(P<0.0001)$ in the HB/RF group. Similarly, there were significantly higher prevalences of pre-existing GI conditions/symptoms $(\mathrm{P}=0.004)$, comorbidities $(\mathrm{P}<0.0001)$ and history of severe NVP or hyperemesis gravidarum in previous pregnancies $(\mathrm{P}=0.03)$ in the $\mathrm{HB} / \mathrm{RF}$ group compared with the controls.

The multiple linear regression analysis revealed that the presence of $\mathrm{HB} / \mathrm{RF}$ could predict $\mathrm{PUQE}$ scores $(\mathrm{P}=0.03)$ as $\mathrm{did}$ pre-existing GI conditions/symptoms $(\mathrm{P}=0.045)$. Similarly, the 


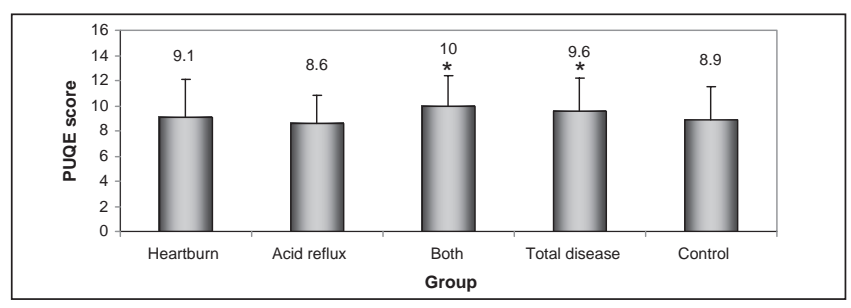

Figure 2) PUQE scores of women experiencing heartburn (HB), acid reflux (RF), both $\mathrm{HB}$ and $\mathrm{RF}$, total disease (including $\mathrm{HB}, \mathrm{RF}$ and both) or no HB/RF. PUQE Pregnancy-Unique Quantification of Emesis and Nausea. ${ }^{*} P<0.05$ compared with control

presence of $\mathrm{HB} / \mathrm{RF}$ solely accounted for the ability to predict Well-being scores $(\mathrm{P}=0.02)$. When only the subset of women experiencing both $\mathrm{HB}$ and RF was analyzed, again, the presence of HB/RF solely predicted PUQE scores $(\mathrm{P}=0.002)$, and Wellbeing scores $(\mathrm{P}=0.006)$.

\section{DISCUSSION}

Our data demonstrate that women experiencing $\mathrm{HB}$ and/or RF in pregnancy experience increased severity of NVP as indicated by validated tools for NVP. Furthermore, assuming women experiencing both $\mathrm{HB}$ and RF have increased severity of disease compared with women who have heartburn alone, trends were observed in which more women experiencing both $\mathrm{HB}$ and RF classified their NVP as severe compared with control, and compared with women only experiencing either HB or RF. These same trends were observed in both the PUQE scores and the Well-being scores, indicating that more severe $\mathrm{HB} / \mathrm{RF}$ symptoms result in increased severity of nausea and vomiting. Despite the dearth of studies examining the relationship between $\mathrm{HB}$ and RF and severity of NVP, several references recommend treatment of $\mathrm{HB} / \mathrm{RF}$ during pregnancy to reduce pregnancy complications (9-13).

Certain potential confounding factors were considered in our multiple linear regression analysis results and demonstrated that the only factor that could consistently account for the increased PUQE scores and the decreased Well-being scores observed in the study group was the presence of HB/RF.

\section{REFERENCES}

1. Nguyen P, Einarson A. Managing nausea and vomiting of pregnancy with pharmacological and nonpharmacological treatments. Fut Med 2006;2:753-60.

2. Miller F. Nausea and vomiting in pregnancy: The problem of perception - is it really a disease? Am J Obstet Gynecol 2002;186:S182-S183.

3. Attard C, Kohli M, Coleman S, et al. The burden of illness of severe nausea and vomiting of pregnancy in the United States. Am J Obstet Gynecol 2002;186:S220-S227.

4. Eliakim R, Ovadia A, Sherer D. Hyperemesis gravidarum: A current review. Am J Perinat 2000;17:207-18.

5. Hod M, Orvieto R, Kaplan B, Friedman S, Ovadia J. Hyperemesis gravidarum: A review. J Reprod Med 1994;39:605-12.

6. Louik C, Hernandez-Diaz S, Werler M, Mitchell A. Nausea and vomiting in pregnancy: Maternal characteristics and risk factors. Paediatr Perinat Epidemiol 2006;20:270-8.

7. Koren G, Pairaudeau N. Compliance with prenatal vitamins. Patients with morning sickness sometimes find it difficult. Can Fam Phys 2006;52:1392-3.

8. Koch K. Gastrointestinal factors in nausea and vomiting of pregnancy. Am J Obstet Gynecol 2002;186:S198-203.

9. Baron T, Ramirez B, Richter J. Gastrointestinal motility disorders in pregnancy. Ann Int Med 1993;118:366-75.

10. Ali R, Egan L. Gastroesophageal reflux disease in pregnancy. Best Prac Res Clin Gastroenterol 2007;21:793-806.

11. Broussard C, Richter J. Treating gastro-oesophageal reflux during

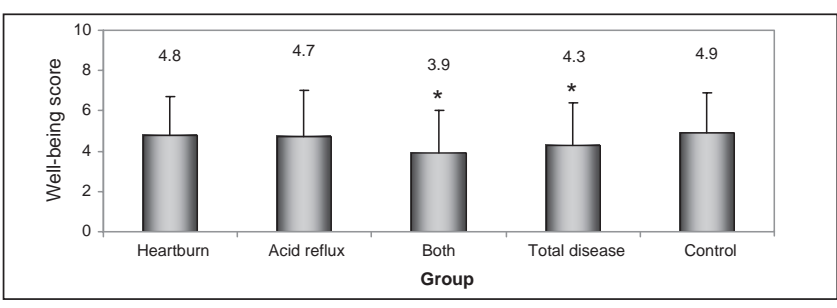

Figure 3) Well-being scores of women experiencing heartburn (HB), acid reflux $(R F)$, both $\mathrm{HB}$ and $R F$ or no $H B / R F$. $* P<0.05$ compared with control

Furthermore, the increased use of antiemetics and antacids observed in the HB/RF group confirms the increased severity of NVP, and the presence of HB and/or RF, respectively.

Our study documents for the first time, a correlation between HB/RF and increased severity of NVP. Future controlled studies should determine whether treatment of HB/RF in pregnancy can reduce the severity of NVP.

CONTRIBUTIONS: SG wrote the paper, conceived of the research proposal, collected the data, conducted the analyses and interpreted the results. CM conceived of the research proposal, collected the data, conducted the analyses and revised the paper. GK conceived of the research proposal, analyzed and interpreted the results, and revised the paper.

DISCLOSURE OF INTERESTS AND FUNDING: The Motherisk NVP helpline is supported by an unrestricted grant from Duchesnay Inc, Canada. GK is holder of the Research Leadership for Better Pharmacotherapy during Pregnancy and Lactation (Hospital for Sick Children, Toronto, Ontario) and the Ivey Chair in Molecular Toxicology (Department of Medicine, University of Western Ontario, London, Ontario).

ETHICS APPROVAL: The study procedures received ethics approval from the Hospital for Sick Children Ethics Committee, the Research Ethics Board. Ethics approval was obtained on May 22, 2008. The Research Ethics Board application number is 1000012298.

pregnancy and lactation: What are the safest therapy options? Drug Saf 1994;19:325-37.

12. Mahadevan U. Gastrointestinal medications in pregnancy. Best Prac Res Clin Gastroenterol 2007;21:849-77.

13. Richter J. The management of heartburn in pregnancy. Aliment Pharmacol Ther 2005;22:749-57.

14. Castro L. Reflux esophagitis as the cause of heartburn in pregnancy. Am J Obstet Gynecol 1967;98:1-10.

15. Marrero J, Goggin P, de Caestecker J, Pearce J, Maxwell J. Determinants of pregnancy heartburn. Br J Obstet Gynaecol 1992;99:731-4.

16. Everson G. Gastrointestinal motility in pregnancy. Gastroenterol Clin N Am 1992;21:751-6.

17. Van Thiel D, Gravaler J, Stremple J. Heartburn of pregnancy. Gastroenterology1977;72:666-8.

18. Fisher R, Roberts G, Grabowski C, Cohen S. Inhibition of lower esophageal sphincter circular muscle by female sex hormones. Am J Physiol 1978;234:e243-7.

19. Van Thiel D, Gravaler J, Stremple J. Lower esophageal sphincter pressure in women using sequential oral contraceptives. Gastroenterology 1976;71:232-4.

20. Koren G, Boskovic R, Hard M, Maltepe C, Navioz Y, Einarson A. Motherisk PUQE (pregnancy unique-quantification of emesis scoring system for nausea and vomiting of pregnancy. Am J Obstet Gynecol 2002;186:S228-S231.

21. Koren G, Piwko C, Ahn E, et al. Validation studies of the Pregnancy Unique-Quantification of Emesis (PUQE) scores. J Obstet Gynaecol 2005;25:241-4. 


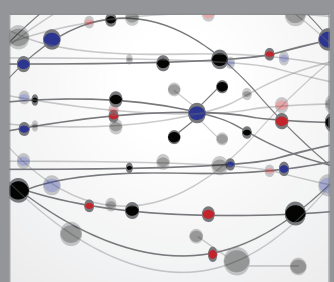

The Scientific World Journal
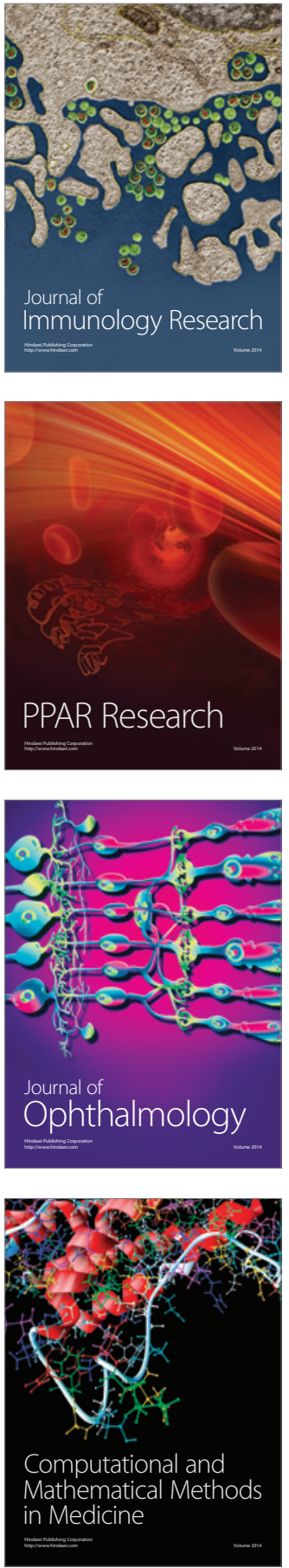

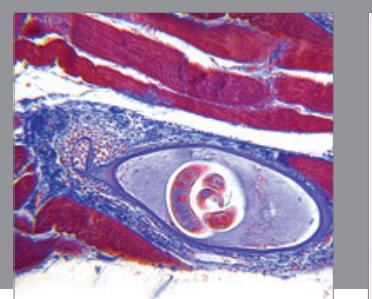

Gastroenterology Research and Practice

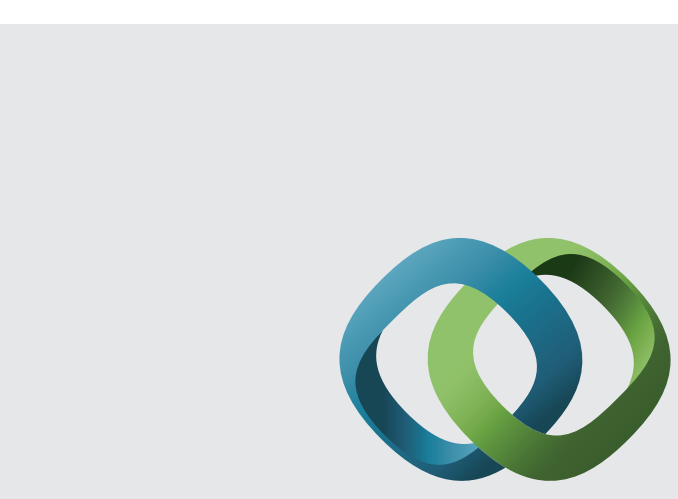

\section{Hindawi}

Submit your manuscripts at

http://www.hindawi.com
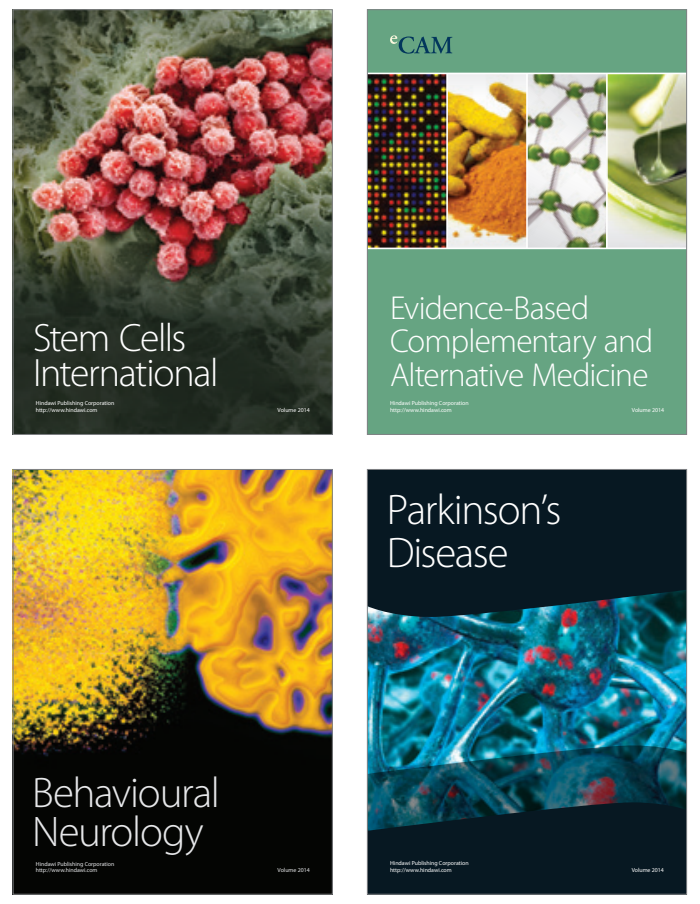
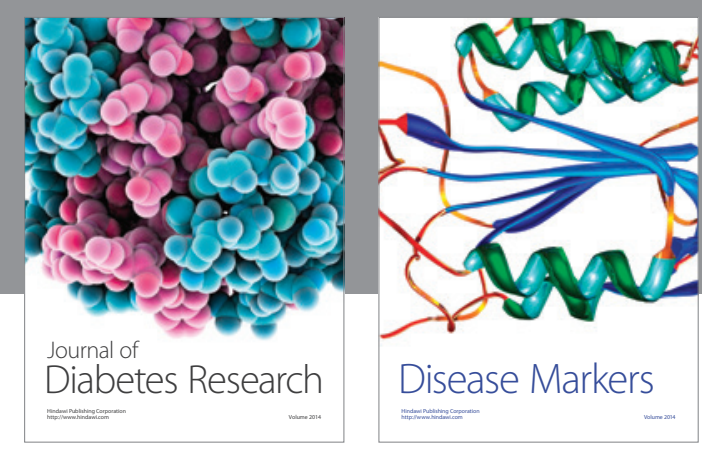

Disease Markers
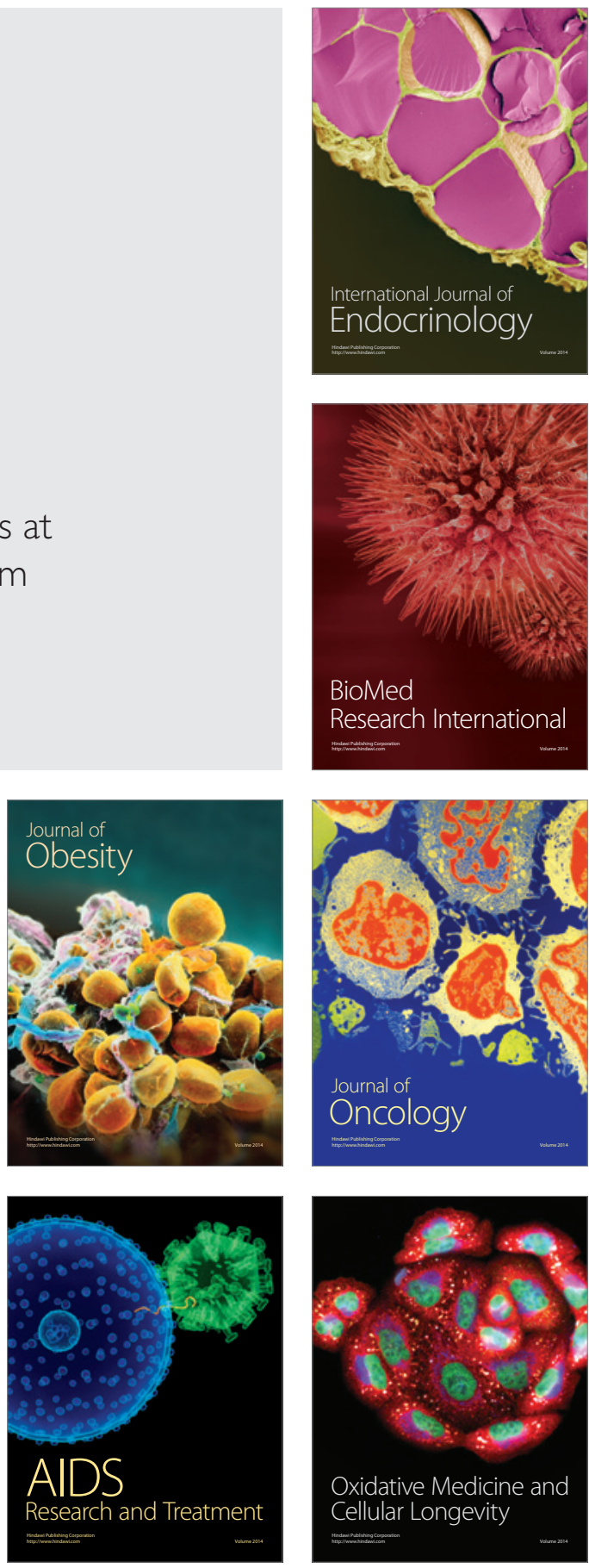